\title{
On the Problems and Countermeasures in English Vocabulary Teaching in Junior Middle Schools
}

\author{
Yanfeng $\mathrm{Zu}^{1, *}$ Zhuo Cheng ${ }^{2}$ Qingping $\mathrm{Sun}^{3}$ and Huijie $\mathrm{Zhao}^{4}$ \\ ${ }^{1}$ Economy and Trade \& Foreign Language, Huali College Guangdong University of Technology, Guangzhou, \\ Guangdong, China \\ ${ }^{2}$ Xiqu Junior Middle School of Zhongshan No.1 Middle School, Zhongshan, Guangdong, China \\ ${ }^{3}$ Economy and Trade \& Foreign Language, Huali College Guangdong University of Technology, Guangzhou, \\ Guangdong, China \\ ${ }^{4}$ Economy and Trade \& Foreign Language, Huali College Guangdong University of Technology, Guangzhou, \\ Guangdong, China \\ *Corresponding author. Email: 740724679@qq.com
}

\begin{abstract}
Vocabulary is the footstone of a language, which plays a pivotal part in language learning. Without Grammar, people's expression would be limited, but without vocabulary, nothing could be conveyed. Taking into account of G Middle School in Shenzhen City, this thesis studies the problems, reasons and countermeasures of English vocabulary teaching in junior middle schools in the presence of observation, questionnaires and interviews from the perspectives of students and teachers. According to the existing problems and causes, this paper puts forward some suggestions on effective English vocabulary teaching.
\end{abstract}

Keywords: Junior middle school English vocabulary teaching, Teaching problems, Teaching countermeasures.

\section{INTRODUCTION}

With the rapid process of science and technology, how to improve students' ability of memorizing and using vocabulary has become a new difficulty. Taking G Middle School in Shenzhen as an example, the research of introduction describes research background of both teachers and students according to the situation of English vocabulary. In order to find out English vocabulary learning reflects the yardstick of English achievement, this part explains research purpose and significance, explaining research methods including questionnaires and character interviews and research content, which analyses the problems of teachers and students in G middle school, so as to put forward some countermeasures efficiently on English vocabulary teaching.

\section{THE PROBLEMS OF ENGLISH VOCABULARY TEACHING IN JUNIOR MIDDLE SCHOOLS}

\subsection{Research Methods}

In the beginning, two classes of grade seven in $G$ middle school in Shenzhen City were selected randomly by classroom observation. From September 1st, 2019 to January 10th, 2020, English teachers and students were surveyed after one semester. There are both of 53 students in grade 7 classes. The average age of the students is 14 and 15. Respectively, the average age of the English teachers who had four years of work experience with a bachelor's degree is 36 . Two teacher tapes are recorded in class, with 10 effective tapes in class. Secondly, 103 questionnaires are given students. They write down in the paper with anonymity, of which 98 collected were valid. Finally, 5 teachers and 10 students are interviewed separately. In order to find out the students' and teachers' real thoughts on the use of vocabulary teaching strategies, some details were recorded and presented. 


\subsection{Research Results}

\subsubsection{The Aspect of Students}

\subsubsection{Negative Study Attitude}

In Elementary Schools, when children begin to learn words, their vocabulary is small and they can cope with transcribing even when they are in a daze. In Junior Middle Schools, the vocabulary gradually increased, the problem came accordingly. $75 \%$ of the students hold negative study attitude, and questionnaires reflect that $68 \%$ of the students do not know how to accumulate words, only to continue to copy.

Phonetics, grammar and translation are distributed into three elements of language, which includes English vocabulary, and it is also the foundation of the four basic skills[1]. English lexicology which is guided by modern linguistic theories is an English vocabulary learning course, embodying the elementary knowledge of words, the significance of words, the building of vocabularies, originating from the alter usage of dialect direction.

In $\mathrm{G}$ middle school, when they have high interest, they memorize lists of words by Rote. When they lost their self-confidence, they will put English books on the table or shelf since students are up against frustration, putting vocabulary behind of anything. It is hard to remember the archetypal English vocabulary provided that a great deal students do not make clear learning schedules, goals and plans.

Approximately $60 \%$ students do not form reasonable vocabulary learning habits, so that $G$ middle school students cannot take vocabulary learning as a separate learning content. Due to students' inactive participation and high tensions of emulating in English classroom, they have little integrated into group collaborative inquiring activities. Those only know one, but do not know the other, students who learn English vocabulary merely stay in one word to translate one meaning or one word to learn multiple usages.

\subsubsection{The Simple Method of Memorizing English Vocabulary}

Through the data of examination, the learning method has been limited due to the students' learning tasks of increasing subjects. Students have strong dependence on vocabulary learning, seldom contact with extra-curricular reading materials, and seldom use inquiry tools, which leads to their low ability of vocabulary learning and application.

Students cannot use the traditional model of rote memorization by learning English vocabulary in G middle school. Such traditional memorization methods cannot be mastered by students effectively. So at the identical time, students blindly memorize words, which lead to confusion in the use of words. For a case, the teacher can lead the students to expand the verb in the unit 6 of the English book, but students who add the suffix mend since the word has shifted from verbs to nouns seem to be difficult. Let students back from the original rote learning background and they can remember the words flexibly as well as cultivating the competence of self-learning.

In $\mathrm{G}$ middle school in Shenzhen, $55 \%$ of the students who want to memorize a large number of words are eager for success, but they forget to review back to the end. This sense of urgency is understandable, and it has also produced a "bear arm" of the consequences: only the pace, regardless of the quality of memory. If they do not review English vocabularies, it is useless to just remember faster and faster.

\subsubsection{The Aspect of Teachers}

\subsubsection{Inactive Teaching View}

Although the study of vocabulary requires a great deal of time and energy from the students themselves, in a sense, the reasonable teaching of the teachers has a direct influence on the students' mastery of vocabulary. With regard to vocabulary teaching, some teachers have a negative teaching attitude, acknowledging that the recognition vocabulary is constantly updated as the language develops, believing that expanding vocabulary is not a myth, and constantly trying various strategies to teach vocabularies.

From the interview, a part of teachers are lack of enough comprehension of the characteristics and laws of the education in the new era, and they may neglect their studies at ordinary times. For example, teachers in $\mathrm{G}$ Middle School have complain that students seem do not respect them, and even want to select students and classes to teach. They often blame others for the quality of teaching, or they think that the school's teaching management is not easy to fit them and the admission policy may be inappropriate. They do not attract students with higher basic qualities who are obedient as before, and they think that today's students are "unique", egotistical and personalized.

\subsubsection{Monotony on English Vocabulary Teaching Methods}

Based on the survey, $67 \%$ of the students think the ways of teaching are monotonous, but $33 \%$ consider it merely effective. Teachers usually explain the superficial meaning of English vocabularies, but the related civilization of these words' connotation is very little to be mentioned. Teachers treat every word equally and have no emphasis on it, resulting in students not knowing which words need to be memorized when 
looking back upon these situations of vocabularies and this adds to the burden of memorizing words.

In order to provoke students' avocation to make good use of English vocabularies, students' correct attitude should be established by availing themselves of idiographic and requisite intelligence to form an intimate knowledge of glossary.

In the daily teaching, because of busy work and other reasons, many teachers know the method, but ignore the teaching method. They just teach the preparation of the vocabulary teaching regardless of English vocabulary learning methods. In the course of expounding new words, teachers often use a simple example to explicate them and renew sentences with similarity to deepen students' understanding. Nevertheless, it is very stressful to learn English vocabulary when students memorize words by rote, facing so many English words. In essence, Rote memorization of English vocabulary is the production of exam-oriented education. Although it can play a role in the examination and achieve good results, students may not be clear about the meaning of vocabulary, and they are easy to forget whose memory is not strong.

\section{THE CAUSATION OF ENGLISH VOCABULARY TEACHING IN JUNIOR MIDDLE SCHOOLS}

In terms of English vocabulary learning, learners can think carefully and consider how to memorize words better, which enhances the enthusiasm for learning foreign languages. According to the aspect of students and teachers, the causes of attitude between students and teachers, studying and teaching methods, as well as teaching content are specific analyzed.

\subsection{The Aspect of Students}

\subsubsection{Little Interested in English Vocabulary}

In modern life, students seldom use English to communicate with overseas. The survey reflects that $58 \%$ of the students feel boring to learn English word, and just $46 \%$ of the students think it is interesting. According to the measurement of investigating questionnaires, a student's accumulation of English words in Grade 7 is approximately 3200, so teachers will encounter more trouble in irrigate new notion for teenagers.

On a survey of G middle school in Shenzhen, half of students are punished by the teacher to copy English vocabulary 100 times, but they just remember the fact that they copied the word 100 times, but do not remember how to write the word. Because of the mechanical transcription, they keep on writing erroneous English vocabularies even if copying a hundred times. The effects of mechanical transcription can run for only a few days, students cannot form longterm memory. There is no denying that if they meet with unfamiliar vocabularies in the course of translation, they will get a major discount translation of the phenomenon with a failure.

In the past, students could read without switching. It takes twice as much effort to memorize English words now. The pronunciation, shape and meaning of this lexicon are in one continuous line, so apprehending English phonetics; transliteration and interpretation go into a fresh challenge. Students learn words and phrases from books in the classroom. What they are familiar with is chatting with their classmates and elders, and they can get new information from the interesting conversation even walking on the street.

Take in by heart, forget by heart. It is no wonder that students in $\mathrm{G}$ middle school used to fill in the blanks and make sentences when they learn English words. Now English pronunciation spelling words and meaning is basically made a word dictation, only by setting a great interest in English vocabulary learning, can students master a great deal English words.

\subsubsection{The Inappropriate Method of Memorization}

First of all, the vocabulary is relatively large, so student studies the way to be quite unitary. In the view of vocabulary teaching in $\mathrm{G}$ middle school, it contains a lot of syntax knowledge with the aggrandizement of quantity and difficulty, which impact students' memory.

Secondly, memorizing English word is merely simple. Through G Middle School, $80 \%$ of the students regard vocabulary as a dispensable learning procedure, lacking English vocabularies consciousness. It is easy to forget to learn vocabulary alone. On the analysis of the survey, $45 \%$ of the students master the spelling of vocabulary, but they cannot grasp its meaning, usage and part of speech firmly. They have inability to use vocabulary flexibly.

Finally, word forgetting is common. Though the observation, two-thirds student learn a new English vocabulary, the speed of forgetting is very fast. In the actual vocabulary learning, students do not have a flexible grasp of vocabulary usage, culture, application, resulting in poor vocabulary learning effect.

Some right way to do timely review and consolidation, that is, repeat. Remember the words they learned in the morning, and repeat them at night before they go to bed. And so on, over and over again, as needed.

In a word, forming the open mind of foreign language vocabulary acquisition, students in $G$ middle school are able to translate foreign language. Thus, it 
acquires a great deal of students to take part in English atmosphere.

\subsection{The Aspect of Teachers}

According to the new curriculum standards and the requirements for vocabulary in the new entrance examination, teachers should analyze the issues and causes existing in G middle school in Shenzhen city, from the aspects of vocabulary phonetics, background, mastery and application of techniques, etc., combining with the $\mathrm{G}$ middle school textbooks. This thesis attests the strategies of vocabulary teaching to exchange their brain storming so as to heighten students' overall English learning capability.

The disadvantages of "time-consuming and inefficient" still exist in studying English lexicon, and here are some the main reasons.

\subsubsection{Negative Teaching Attitude}

Some teachers in $\mathrm{G}$ middle school are deeply influenced by traditional educational concepts, so their ideology and knowledge with outdated concepts cannot keep up with the development and requirements of the times. Undisciplined students are not equal, so teachers have to hold the teaching activity passively in the sound of lamentation or complaint, to arouse students' antipathy, tense relationship between teachers and students accordingly.

Influenced by traditional educational concepts, English teachers in $\mathrm{G}$ middle schools spend less than 10 minutes on vocabulary teaching and lay little stress on their own in one class, so G middle school students do not enlarge their English vocabulary. It is well-suited to cultivate a nice custom in the long run, but it will straightly impact students' learning productivity. In vocabulary teaching, some English teachers do not have clear focus and goals, and they do not carry out English teaching according to the syllabus. There are also some English teachers who don't have any guidance for students. They usually explain the meaning of the English words which are read by students, eventually, students will have trouble remembering words to reverse psychology, making it more challenge to master vocabulary well [2].

\subsubsection{Isolating the Application of English Vocabulary}

From the teaching practice, a part of students apt to play tricks, ask the foreman for the words tested, and then concentrate on learning and memorizing the words tested. At the same time, teachers make students write words by heart on the blackboard. Most students think it will be very embarrassed if they write the words incorrectly, so they are not interested in the way of memorizing to urge students to learn, they are even disgusted by it. In addition, using a way of examination that is the group leader assessment, mutual examination at the same table, is easy to cheat. In short, the traditional assessment model is complicated to see the availability of vocabulary [3].

Teachers' teaching methods in the $\mathrm{G}$ middle school are not reasonable enough. They do not grasp the newfashioned teaching innovation, which cause them not carry out teaching activities in accordance with the actual conditions of students' receptive ability and learning needs [4]. In class time, teachers should follow the proper course from theory to theory and books. If they lay too much stress on theoretical knowledge and give a cold shoulder to students' training of technical ability, students will neither confide logical spin in mind, nor learn occupational skills. Compared with other class, the teaching trait of teachers is relatively ordinary, thus causing students' discontent. Taking a simple teaching example, the grammatical feature of the word apple is that the word is countable and plural, and the first syllable is a vowel, so the correct expression of an apple is an apple, because it involves the rules of usage of the indefinite article.

Teaching words in isolation from the form, sound and meaning of words. Research shows that teachers in $\mathrm{G}$ middle school merely teach them to read the words on the blackboard repeatedly. Sometimes students try to get rid of the implication of the bad memory, but Chinese characters were adopted to mark the sounds. For example, one student used the Chinese pronunciation after the word "student", or another student used the word "tomorrow" after the word "special cat meat". It is because of the students' poor recognition of English appearance or the teachers' applicable implement which not only affects students' vocabulary memory, but enable students to lay a solid foundation for lifelong learning.

\section{THE COUNTERMEASURES OF ENGLISH VOCABULARY TEACHING IN JUNIOR MIDDLE SCHOOLS}

Due to the particularity of English words, teachers should use flexible and tactful teaching adequacy to fabricate well-designed and equitable setups in English vocabulary teaching. This chapter mainly analyses the different aspects of students and teachers, including the methods of memory, enlargement of vocabulary, and word review. Apart from it, spelling rules of vocabulary, combining teaching content and showing multilevel meaning are also important countermeasures by teachers. 


\subsection{The Aspect of students}

\subsubsection{Remember by Phonological Regularity}

Language learning is a step-by-step regularity, but it requires numerous pupils to follow. To be honest, English and Chinese have identical disciplinarian in teaching. Recalling when students were in the first grade of Primary School, the language teacher attached great importance to our rhyme study. As for English, they should also pay attention to the teaching of English phonetic symbols. If the students learn the phonetic symbols, they can spell the words in the light of their regular pattern [5]. After learning some words, this requires students to strengthen the study of pronunciation rules.

Although teachers help students to form good habit, it is this book about teacher compilation of "the golden key to solving problems" that lets many students fall in love with English completely. From this book, students understand the concept of syllable for the first time, and distinguish the difference of open syllable and closed syllable or even other important basic concepts in English. Why are they important? For instance, if they master the basic concepts of closed syllable and open syllable, it will be of great help to them in spelling and reciting words correctly. After mastering the two concepts mentioned above, students learned English phonetics systematically. Once again, when students just read Primary School Chinese textbooks, the teacher is to teach them the Chinese initial consonant, vowel and other basic knowledge. If students grasp these regulations, they will be capable to remember English words probably as a result of Pinyin. For English, after teachers teach our students English alphabet songs, they should also teach them the correct spelling and writing of the 48 phonetic symbols. If students understand the pronunciation rules and phonetic symbols, they will no longer mark Chinese characters.

Hegel once said that music is a fluid building. The effective memory of music depends on the learners 'cognition about this architecture. On the basis of understanding the mode of music memory is more instructive to the design of sociologist teaching system, music practice-music thinking-self-organization is proposed as the development mode of Melody Memory. Through the insight into the General Law of music memory, so students should remember by phonological regularity.

\subsubsection{Expand Vocabulary by Word Formation}

The type of English word is one of the most momentous designations to gauge one's English horizon. If students want to study vocabulary well, they can dispense it without a certain vocabulary. To know English word-formation, to master English root, prefix and suffix is one way to enlarge vocabulary rapidly. It is not the only one to ameliorate English reading velocity and intellect, but fast promote the advance of cognition. English word-formation is a basic skill for $G$ middle school students. Most importantly, it is beneficial for them to amplify their strong suit and create it succeed in the future.

Roots and affixes are a pair of brothers who support and influence each other. In a derived word, the root is the main word, and the affix is the auxiliary word. The significance of a paraphrase also has a lot to do with its origin, which is customarily meaningful news. Manual means "hand"; script means "write". Manuscript is written by hand. It adds up to "manuscript." Many words can be used in this way, but the actual situation is much more complicated. The origin of a word has a long history, so they need to construct new language surroundings to study. After many years of various political, historical, geographical and other factors, the direct use of root meaning plus affix meaning of the sum of the derivation of words may have a greater change.

Therefore, some learners will respond that the root affix that cannot explain the meaning of a lot of words. Root affixes are used to help people better understand and remember words, thinking over the actual situation. But to measure the reliability of a method, they need to think highly of its consequence, its heart ingenuity as well, efficiency, feasibility and so on. The biggest problem with memorizing words to improve your vocabulary is that it's a very inefficient way to do it.

Vocabulary is on basis of experience accumulation in English learning, and words examination test is to indicate students' deficiency how to make good use of English vocabularies. The focus of the lexical part is on the collocation of words and fixed phrases. The principle morpheme sense can consist of four pattern namely, lexicology, semantics, lexicography and etymologist. The outline requires students to recognize and examinee the words, be aware of the usage of the grammars as well as sentence. It requires students to paragraph sentences accurately and differentiates the Synonyms and Antonyms, which applied in a real world.

\subsection{The Aspect of Teachers}

\subsubsection{Improve Vocabulary Teaching Ways in Class by Spelling Rules}

Through the observation, teachers in $G$ middle school are weak in teaching practice. Although they have got the corresponding teachers' aim requirement, they do not come into being context reality. For example, the lack of relevant knowledge about the curriculum, poor language skills and weak teaching organization, they cannot validly undertake the task of 
teaching the curriculum. In the process of teaching students, these teachers often feel inadequate and ineffective, so arouse students' dissatisfaction. Dealing with the above problems, schools need to transform a new objective and project, comply with the orderliness of teachers' professional proposal. Regardless of educators' supervision and educates' self-administration, teachers become aware of the direction of rectification to reform as soon as possible.

According to English vocabulary teaching, the combi-national rules of letters should be obeyed, so students can feel familiar with the words by perceiving the articulation of vocabularies by imitation. This kind of natural spelling method has its inevitable significance and special use, highly influenced by English teachers. The essence of the English vocabulary spelling is to let students comprehend the meaning of English words, where each word has a certain law of letter shape formed by units. The research shows that about $80 \%$ of the vocabulary conforms to the rules of phonological correspondence.

Apart from it, the use of English artless spelling is significant assist students to clear the coalescence of compound words. Teachers can utilize the coalescent of letters to aid students to transliterate learning especially are those of vowels and consonants and those of pure consonants. Let the students repeatedly comprehend the characteristics of vowel-consonant, and learn a wide range of collocation as soon as possible, which can help expand the vocabulary. As English words become more difficult, it can also be extended to simple consonant combinations.

\subsubsection{Combine Sentence, Phrase and Text with Teaching}

English words have many derivatives and compounds, thus teachers should put focal point on students' perception through observation and thinking. Students can remember the words according to these rules. In this process, teachers should consciously train students' ability of thinking, let students try to find and generalize these rules, and let them master the rules of English word formation while learning an English word. Vocabulary learning should not be isolated, teachers should put vocabulary into specific sentences and articles, so that students can really understand and use the words.

Combining sentence, phrase and text to teaching, teachers should reorganize stuff and make out teaching modification flexibly in the light of students' identification demand and level, so as to activate students' tension efficiently. Creative use of textbooks can not only make students more interested in learning words, but also effectively make up for the lack of vocabulary in textbooks and expand it. Teachers need to lay more stress on the aim of materials, especially the breadth and depth of momentous vocabularies, which will have a greater impact on students' cognitive preservation. The wisdom of English vocabulary teaching is required to think highly of the logical similarities full of emotion, and the comparison of words, so do theirs endeavor to enlarge it appropriately. Teachers should be absorbed in students' progressive development and movement.

\subsubsection{Show the multilevel meanings of words in context}

Without context, any word would be meaningless. As Language words are let into in context to be alive, easy to recall, and easy to apply. To be a commander of English words, teachers should integrate students into the idiographic situation, guiding them to study cheerfully. Students have already mastered word recognition through guessing linkages between the contexts of passage.

Aiming at the matter of one-size-fits-all in English Vocabulary Teaching, this writing classifies a various orientation. It is syllabus taken for granted that the students should master the words as well as emulate it in different levels, which can enhance their confidence and improve the learning effect. In the meanwhile, the characteristics of vocabulary itself can classify words such as polysemy, synonym, or antonym.

Modern multimedia technology can be used to explain vocabulary. For example, teachers can use multimedia equipment to show some funny pictures, which can not only enliven the classroom teaching atmosphere, it also allows students to speculate or guess what the word means and how it is used. It is worth being mentioned that there are numerous approaches in teaching, and the most concern is to actualize them rationally in the manner of the students' condition. Apart from it, task-based practice, communicative vocabulary, word-building analysis and word association can be used in teaching.

\section{CONCLUSIONS}

For students, the research mainly focuses on pulling corresponding observation, questionnaires and interviews in $\mathrm{G}$ middle school. For English teachers, the thesis takes more notice of the tactics of vocabulary teaching, which could be suitable for all $G$ middle school students. What is more, these new teaching modes can be applied in daily life to improve teaching efficiency.

According to the outcomes of the research, English vocabulary teaching is required to change both the side of students and teachers. From the aspect of students, their negative study viewpoint, unsophisticated memory and English vocabularies misuse are the chief matters in 
$\mathrm{G}$ junior middle school. From the aspect of teachers, the problems are that their inactive teaching notion, monotonous techniques and illustrating the implication of words out of the content. Thus the plight are that little interest and inappropriate ways of memorization for students as well as passive teaching attitude and isolating the application of English vocabulary learning for teachers. Therefore, corresponding countermeasures should be adopted by students and teachers. As for students, it is necessary to remember by phonological regularity, expand vocabularies by word formation and consolidate promptly. As for teachers, they need to alter vocabulary teaching notions by spelling rules, combining sentence, phrase and text to teaching and showing the multilevel meanings of words in context. Teachers should give it shot beneficial qualification to fit students' aggressiveness and devotion, and do their utmost to show consideration for physical and mental health, so as to supply high-quality teaching service and management for their employment and promotion.

New English vocabulary learning method is going to throw down the glove conventional teaching modes, so the majority of middle students are conceiving that they can obtain recognition from these ways. In order to motivate students to study hard, the government must ask teachers to love students, actively understand their learning, living, and thinking. The schools must adopt the management mode of "follow-class study as a qualified teaching", and teachers should carry out the system of "training first, and then getting on the job, then improving", actively participate in multiple campaigns such as class estimation, conjunct instruction target and so on. Students should carry on accumulating vocabularies and experiences.

In the course of carrying out teaching activities, teachers should organically combine with their aptitude to teach students to keep pace with the times, make great efforts to prepare lessons without forgetting the "students". They should try to make lesson project reasonable, make the teaching substance moderate, and make their countermeasures conform to the reality, to form a positive interaction between classroom and daily life. Students also actively participate and integrate into the class activities, which increases the volume of English vocabulary.

There are some systematical limitations in virtue of the restricted time of abstracting scope of research. The advantages and disadvantages of English vocabulary teaching only can be revealed partly by the samples in $\mathrm{G}$ middle school, which lacks much higher popularity. Thus, it needs more research information and details to lead a convincing conclusion. Studies are required to conduct a useful test for the Grade 7 members, and two years experiment works on the research will be better.

\section{ACKNOWLEDGMENTS}

Fund: Achievements in A Study on the Effectiveness of College Students' Vocabulary Memory Based on the Perspective of Psycholinguistics, Guangdong Education [2017] No. 45

\section{REFERENCES}

[1] Bisson Marie-Josée, van Heuven Walter J B, Conklin Kathy, Tunney Richard J. "Incidental acquisition of foreign language vocabulary through brief multi-modal exposure" [J]. PloS one, 2013, 8 (4).

[2] Schlechter Alan Daniel, O'Brien Kyle H, Stewart Colin. "The Positive Assessment: A Model for Integrating Well-Being and Strengths-Based Approaches into the Child and Adolescent Psychiatry Clinical Evaluation" $[\mathrm{J}]$. Child and adolescent psychiatric clinics of North America, 2019, 28 (2).

[3] Pan Xuejiao. "The Cultivation of the Core Quality of Junior Middle School Students in English Teaching In Chinese." [J]. Curriculum Education Research, 2020(03):126 - 127.

[4] Statistical Word Learning and Object Categorization: A Cross-Linguistic Study in English and Mandarin. 2009, 31.

[5] Yuan Mulin. "A Study of English Listening Teaching in Junior Middle School from the Perspective of Multimodal Theory In Chinese." [J]. Comparative Study of Cultural Innovation, 2019, 3(29):137 - 138.

[6] Stuart C P. An Introduction to Linguistics [M].London: Macmil- lan Publishers Ltd., 2000. 